\title{
PREVALENCE OF RAPID WEIGHT LOSS PRACTICES AND THEIR PROFILES AMONG NON-ELITE COMBAT ATHLETES IN KUCHING, EAST MALAYSIA
}

\author{
WHYE LIAN CHEAH', MYAT SU BO², WINNIE ANAK KANA3, NUR IRDINA BINTI MOHD \\ TOURISZ3 ${ }^{3}$ MOHAMAD ARIF HADZIMI BIN ISHAK ${ }^{3}$, MAHANAGARAANI YOGESWARAN3 \\ University of Malaysia, Sarawak, Faculty of Medicine and Health Sciences ${ }^{3}$, Department of Community \\ Medicine and Public Health', Department of Basic Medical Sciences², Sarawak, Malaysia
Mailing address: Whye Lian Cheah, University of Malaysia, Sarawak, Faculty of Medicine and Health Sciences, Department of Community Medicine and Public Health, Jalan Datuk Mohammad Musa Street, 94300 Kota Samarahan, Sarawak, Malaysia, tel.: +60 82 581000, e-mail: wlcheah@unimas.my

\begin{abstract}
Introduction. Rapid Weight Loss (RWL) is a common practice in combat sports where weight is classified to ensure equitable competition in terms of strength and agility. This study aimed to investigate the profiles of non-elite combat athletes and their RWL practices. Material and methods. This research was a cross-sectional study conducted in Kuching, Sarawak. Data were collected using a validated self-administered dual-language questionnaire. Results. A total of 65 respondents participated in the study; two-thirds were male, and the majority were taekwondo athletes. About $66 \%$ of the respondents reported to have practised rapid weight loss, with average weight loss of $3.4 \mathrm{~kg}(\mathrm{SD}=1.90)$ and highest weight loss of $4.9 \mathrm{~kg}(\mathrm{SD}=3.16)$. The most common RWL methods used were exercising more (69.8\%), gradual dieting (51.1\%), and training in heated rooms (20.8\%). Physical trainers and training colleagues were rated as persons having the most influence on the use of RWL by the respondents. The perceived adverse effects which were mentioned the most frequently by the respondents were fatigue (69.2\%), decreased vigour (50.8\%), and muscle cramps (46.2\%). As for the type of combat sport practised, muay thai and jiu jitsu had the highest number of respondents who used RWL. There were significant differences in RWL practices depending on the influences of training colleagues, physicians/doctors, physical trainers, parents, dieticians, and former athletes as well as perceived adverse effects of RWL. Conclusions. The findings of the current study were observed to be similar to those of research involving elite combat sport athletes where the prevalence of RWL was reasonably high, with similar characteristics. A proper regulatory programme should be put in place to assist both the athletes and their coaches/trainers in implementing proper weight control.
\end{abstract}

Key words: striking and non-striking combat sports, extreme weight loss, perceived adverse effects of rapid weight loss

\section{Introduction}

Combat sports refer to a group of sports that involve direct combat between two athletes [1]. Because of the nature of the sport, which involves elements of body contact that include striking, throwing, and grappling an opponent, it has been suggested these sports are dangerous and harmful compared to other sports [2]. Combat sports can be classified into striking or non-striking sports (involving grappling or throwing an opponent or immobilising them). Some examples of striking combat sports are taekwondo, karate, and boxing, where one strikes the opponent directly by kicking and punching them or with the use of weapon. On the other hand, non-striking sports do not allow direct striking, and the athletes who practise them do not wear protective equipment. Some examples of non-striking sports are wrestling, judo, and jiu-jitsu [3].

In combat sports, anthropometry is commonly used to determine the performance of athletes [4]. Understanding body composition (in particular body muscle and fat) can help athletes classify for the desired weight category [5]. For example, in non-striking sports such as judo, athletes need high levels of upper body anaerobic power and capacity as well as strength to achieve better performance [6]. However, in taekwondo and karate (striking sports), the competitors' focus is more on agil- ity, strength, and leverage [5]. Dubnov-Raz et al. [7] have recommended that height categories should be used instead of weight categories in striking martial arts competitions as height gives more advantage in sports like karate and taekwondo, where fighting occurs at a relatively close distance. The type of competition also determines the percentage of muscle and fat required. This is evidenced in judo athletes, where lower body fat percentage was found among athletes competing in higherranking competitions, on the Olympic and non-Olympic levels [5].

Rapid weight loss is an act of losing weight in a short time to reach the standard necessary to compete in a specific weight class. It is characterised as transitory weight loss of no less than $5 \%$ of one's weight within a short period of time (a week) [8]. In some situations, RWL can be practised as late as the day before the competition. RWL is a common practice in combat sports where weight is classified to ensure equitable competition in strength and agility [9]; combat sport athletes use Rapid Weight Loss (RWL) to enter at the top band of a lower weight category and have a greater chance of winning [10]. While weight classification is used for ethical reasons, many combat athletes have cultivated the undesirable practice of RWL to gain a physical advantage over smaller, weaker, and lighter opponents. 
A prevalence of RWL as high as 60-90\% was observed in several studies that investigated wrestling and judo competitions [5]. Such practices are commonly found at higher competition levels, where more aggressive weight management strategies are used. RWL is practised regardless of age, gender, competition level, or weight class $[5,9]$. In some combat sports such as judo, RWL was observed in athletes as young as 12-15 years old [5]. Some common RWL techniques used are increased exercise; dehydration; using sauna and wearing rubber/plastic suits; reducing energy intake; using rubber/plastic suits during training; low carbohydrate intake; fat restriction; fasting; vomiting; and intake of diet pills, laxatives, and diuretics; all these can be harmful to athletes' health and performance, as well as increasing the risk of injury $[11,12,13]$.

Among the individuals who influence RWL practices, coaches have been rated as the most influential in impacting the weight management behaviour of combat sport athletes [5, 13, 14]. Unlike elite athletes, non-elite athletes tend to rely on their coaches to manage their training schedule and often have no support from professional personnel such as personal trainers, doctors, and nutritionists. Parents can play an important role, but their influence diminishes as athletes age [15].

RWL has negative health consequences for athletes, both physical and psychological, including lower bone density; poorer muscular performance; worsened mood; increased risk of sport injury; dehydration; increased heart rate; decreased anaerobic performance; decreased short-term memory, vigour, and concentration; as well as increased confusion, rage, fatigue, depression, and isolation $[11,16]$. However, in a study on the knowledge of RWL carried out among adult British judo athletes, the most common side effects of RWL perceived by the athletes themselves were injury risk and slowed reaction time [8]. Despite knowing the adverse effects and health consequences of RWL, combat athletes still took up RWL, which seems to indicate an apparent paradox between their perceptions and their practice. A study conducted among amateur boxers showed that the boxers associated RWL with good performance and saw losing much weight prior to the competition as an element of the sport providing positive reinforcement [17]. In certain combat sports, practising RWL is thus considered to be normal and be part of the tradition and culture of the sport [18]. In addition, Pettersson et al. [18] discovered that in order for combat athletes to cope with pressure, self-doubt, and anxiety, they would focus on controlling their diet and body weight as part of a self-disciplinary approach. The results of a study conducted in Brazil among judo athletes practising RWL showed that it was harmful, but the adverse effects were temporary and could be normalised within a short period of time [19].

To date, there has been a dearth of research determining the prevalence of RWL and its profile locally. Furthermore, most of the literature focused on elite combat athletes who trained under a structured institution. This study aimed to explore the profile of RWL among non-elite combat athletes in Kuching in Sarawak, Malaysia.

\section{Material and methods}

The research was a cross-sectional study carried out among non-elite combat sport athletes in Kuching, Sarawak. Nonelite athletes are defined as those who are not national and/ or international competition medallists but have participated in smaller-scale competitions under associations or clubs. The most popular combat sports found in Kuching are karate, jujitsu, taekwondo, judo, silat, and muay thai. In Kuching, there are many unregistered formal and informal combat sports athletes, which made it difficult to compile a list of combat athletes. Nevertheless, a list of existing clubs or associations was obtained through the internet and public enquiry. To make sure there was equal representation from each combat sport, the sampling frame was designed to include at least 1-2 clubs or associations for each combat sport that had the highest membership. The inclusion criteria were the following: the subject had to be a combat athlete aged 15 and above who had participated in a formal competition in the past two years. Sample size was calculated based on the formula proposed by Dhand and Khatkar [20]; the prevalence of RWL practice was expected to be $92.5 \%$ [15], with $5 \%$ absolute precision and a 95\% confidence interval. Total estimated sample size with 5\% attrition was 118 .

Prior to the date of data collection, we approached the person in charge of the clubs/associations in order to obtain permission to conduct the study before a meeting was held with the potential respondents. Once permission was granted, a short briefing was organised to explain the procedure of the study, and informed consent forms were distributed. For those who were under 18 years old, the consent form was distributed together with a research information sheet for the parents.

Data were collected using a self-administered questionnaire, translated into Bahasa Malaysia using back-to-back translation. The questionnaire consisted of six sections: (1) socio-demographic profile; (2) combat sport profile; (3) rapid weight loss profile; (4) self-reported history of weight loss; (5) perceived influence on weight loss; (6) awareness with regard to the adverse effects of RWL. Pre-testing of the questionnaire was done, and reliability analysis yielded a Cronbach alpha of 0.731 , which indicated the questions were reliable. No correction was needed in terms of the language or format of the questionnaire.

The practice of RWL was investigated through the use of a questionnaire adapted from Artioli et al. [21]. The questionnaire consisted of seven items, and a special scoring system was used. If the respondent had undergone RWL practices, 3 points were given, whereas 0 points were given to those who had not. For those who practised RWL, 0.5 point was given per kilogram for the most weight loss. For the usual weight cut before the competition, one point was awarded for 1 kilogram lost. The respondents received scores of $5,4,3,2,1$, and 0 when they took 1-3 days, 4-5 days, 6-7 days, 8-10 days, 11-14 days, and 14 and more days to lose weight, respectively. One point was given per kilogram for weight gained a week after the competition. For the methods used to lose weight, the scores were $0,0.5,1,2$, and 3 when the respondent responded "never", "not anymore", "almost never", "sometimes", and "frequently", respectively. Total scores were calculated, and higher scores corresponded with more aggressive weight loss utilising harmful methods and a higher risk of rapid weight loss.

The self-reported history of weight loss section consisted of three questions. The first question concerned the weight class the respondents competed in. The second question regarded whether the respondent had changed his/her weight class. The last question enquired about the weight category of the athletes during the previous off-season. As for the perceived influence on weight loss, the questionnaire enquired about the individuals who influenced the athlete's decision to lose weight. The individuals listed were training colleagues, physicians or doctors, physical trainers, coaches, parents, dieticians, former athletes, and others. The level of influence was measured using a Likert scale of 5 (not influential, slightly influential, unsure, somewhat influential, and very influential). The last section of the ques- 
tionnaire enquired about the respondents' awareness with respect to the adverse effects of practising RWL.

Statistical analysis was performed with the SPSS Statistics package 22. Data were cleaned and checked for normality before proceeding to inferential statistics. In descriptive analysis, percentages, means, and standard deviations were used. For inferential analysis, chi-square and Fisher's exact tests were used to find the association between two categorical variables. The independent samples t-test was applied to compare the mean values of continuous variables. For all analyses performed in the study, the confidence interval was $95 \%$, and a p-value of less than 0.05 was considered to be statistically significant.

\section{Results}

A total of 12 associations/clubs were visited, and only 65 respondents gave consent to participation, making the response rate $55 \%$. There were more male respondents than female respondents $(67.7 \%$ vs. $32.3 \%)$. Mean age was 22.9 years $(\mathrm{SD}=$ 6.80 ). More than $40 \%$ of the respondents practised taekwondo, followed by muay thai and other combat sports. About $66 \%$ of the respondents reported to have practised rapid weight loss, with average weight loss of $3.4 \mathrm{~kg}(\mathrm{SD}=1.90)$ and highest weight loss of $4.9 \mathrm{~kg}(\mathrm{SD}=3.16)$. More than one third of those who practised RWL claimed they could achieve their ideal weight loss in less than 7 days. More detailed information on the sociodemographic and sport profile of the respondents is presented in Table 1.

Table 2 presents the method of rapid weight loss used by the respondents, with the top three methods being exercising more $(69.8 \%)$, gradual dieting $(51.1 \%)$, and training in heated rooms $(20.8 \%)$. The least used methods were diuretics, vomiting, diet pills, and spitting, which more than $60 \%$ of respondents claimed that they had never used.

As for persons who had an influence on the respondents' use of RWL, physical trainers and training colleagues were perceived as having the most influence, with $51.2 \%$ and $46.5 \%$ of "very influential" responses, respectively (Tab. 3).

Table 4 presents the perceived adverse effects of RWL from all the respondents. The perceived adverse effects mentioned the most often were fatigue (69.2\%), decreased vigour $(50.8 \%)$,
Table 1. Socio-demographic and combat sport profiles of the respondents $(n=65)$

\begin{tabular}{|c|c|c|}
\hline & $\mathrm{n}(\%)$ & Mean (SD) \\
\hline Age (year) & & $22.9(6.80)$ \\
\hline \multicolumn{3}{|l|}{ Sex } \\
\hline Male & $44(67.7)$ & \\
\hline Female & $21(32.3)$ & \\
\hline \multicolumn{3}{|l|}{ Ethnicity } \\
\hline Malay & $26(40.0)$ & \\
\hline Chinese & $22(33.8)$ & \\
\hline Others & $17(26.2)$ & \\
\hline \multicolumn{3}{|l|}{ Type of sport practised } \\
\hline Taekwondo & $29(44.6)$ & \\
\hline Muay thai & $14(21.5)$ & \\
\hline Other (karate, judo, silat) & $13(20.1)$ & \\
\hline Jiu jitsu & $9(13.8)$ & \\
\hline \multicolumn{3}{|l|}{ Profile of sport practice } \\
\hline Age of beginning to practise (year) & & $14.7(5.69)$ \\
\hline Age of beginning to compete (year) & & $16.6(4.75)$ \\
\hline $\begin{array}{l}\text { Most weight cut for competition }(\mathrm{kg}) \\
(\mathrm{n}=43)\end{array}$ & & $4.9(3.16)$ \\
\hline $\begin{array}{l}\text { Weight usually cut before competition }(\mathrm{kg}) \\
(\mathrm{n}=43)\end{array}$ & & $3.4(1.90)$ \\
\hline \multicolumn{3}{|l|}{ Duration of weight reduction $(n=43)$} \\
\hline$>14$ days & $16(24.6)$ & \\
\hline $7-14$ days & $11(25.6)$ & \\
\hline$<7$ days & $16(37.2)$ & \\
\hline Rapid weight loss & $43(66.2 \%)$ & \\
\hline
\end{tabular}

Table 2. Weight loss methods used $(n=43)$

\begin{tabular}{|c|c|c|c|c|c|}
\hline Types & Always (\%) & Sometimes (\%) & $\begin{array}{c}\text { Almost never } \\
(\%)\end{array}$ & Never (\%) & Not anymore (\%) \\
\hline Gradual dieting & 51.1 & 32.6 & 4.7 & 9.3 & 2.3 \\
\hline Skipping meals & 14.0 & 39.5 & 7.0 & 34.8 & 4.7 \\
\hline Fasting & 14.0 & 41.8 & 7.0 & 30.2 & 7.0 \\
\hline Restricting fluid consumption & 18.7 & 20.9 & 9.3 & 39.5 & 11.6 \\
\hline Exercising more & 69.8 & 20.9 & 2.3 & 4.7 & 2.3 \\
\hline Training in heated room & 20.8 & 34.9 & 14.0 & 23.3 & 7.0 \\
\hline Sauna & 2.3 & 11.6 & 16.3 & 48.8 & 21.0 \\
\hline Wearing rubber suit & 18.6 & 21.0 & 11.6 & 37.2 & 11.6 \\
\hline Wearing winter suit all day & 0.0 & 25.6 & 9.3 & 48.8 & 16.3 \\
\hline Spitting & 4.6 & 4.6 & 4.7 & 62.8 & 23.3 \\
\hline Laxatives & 0.0 & 2.3 & 7.0 & 58.1 & 32.6 \\
\hline Diuretics & 0.0 & 4.7 & 2.3 & 62.8 & 30.2 \\
\hline Vomiting & 0.0 & 9.3 & 7.0 & 62.8 & 20.9 \\
\hline Diet pills & 0.0 & 2.4 & 9.3 & 67.4 & 20.9 \\
\hline
\end{tabular}


Table 3. Persons influencing weight loss $\left(n=42^{*}\right)$

\begin{tabular}{|l|c|c|c|c|c|}
\hline & $\begin{array}{c}\text { Not influential } \\
(\%)\end{array}$ & $\begin{array}{c}\text { Slightly } \\
\text { influential (\%) }\end{array}$ & $\begin{array}{c}\text { Unsure } \\
(\%)\end{array}$ & $\begin{array}{c}\text { Somewhat } \\
\text { influential (\%) }\end{array}$ & $\begin{array}{c}\text { Very } \\
\text { influential (\%) }\end{array}$ \\
\hline Training colleague & 7.0 & 16.3 & 9.3 & 20.9 & 46.5 \\
\hline Physician & 44.2 & 11.6 & 25.6 & 18.6 & 0.0 \\
\hline Physical trainer & 9.3 & 4.6 & 9.3 & 25.6 & 51.2 \\
\hline Coach & 2.3 & 4.7 & 23.3 & 69.7 & 0.0 \\
\hline Parents & 34.8 & 4.7 & 20.9 & 23.3 & 16.3 \\
\hline Dietician & 39.5 & 16.3 & 20.9 & 11.7 & 11.6 \\
\hline Former athlete & 21.0 & 11.6 & 11.6 & 27.9 & 27.9 \\
\hline Others & 74.4 & 2.3 & 9.3 & 7.0 & 7.0 \\
\hline
\end{tabular}

* -1 respondent did not respond.

and muscle cramps (46.2\%). More detailed information can be found in Table 4.

Table 5 presents the results of a univariate analysis with RWL practices as a dependent variable and the socio-demographic and combat sport profiles as independent variables. There was a nearly equal percentage of male and female respondents who practised RWL. Among the types of combat sports, muay thai and jiu jitsu had the highest number of respondents who practised RWL (92.9\% and 88.9\% respectively). Among the respondents who practised RWL, physical trainers (76.7\%), coaches $(93.0 \%)$, and training colleagues $(67.4 \%)$ were reported to have the most influence on the RWL practice. The univariate analysis indicated there were significant differences in RWL practice depending on whether it was influenced by training colleagues, physicians/doctors, physical trainers, parents, dieticians, or former athletes. The results also revealed there was a difference in RWL practice depending on the perceived adverse effects of RWL.

\section{Discussion}

This current analysis is the first attempt to examine the prevalence of rapid weight loss among non-elite combat athletes in Kuching. The findings showed that $66.2 \%$ of the respondents had practised rapid weight loss within the past two years. Although this figure was not as high as those for athletes practising other combat sports such as wrestlers $(68-89 \%)[14,22]$ or judo athletes (86\%) [23], it indicates that the practice of RWL is still prevalent among combat sports athletes regardless of the type of sport or competition level. In boxing, for example, amateur boxers have three phases in the weight control programme depending on whether they are taking part in an interclub or championship competition [24]. In our sample, although the respondents were not elite athletes, the prevalence of RWL could still be considered reasonably high. There are many reasons as to why combat athletes practise RWL, the most common ones being the pressure to conform to a specific body size, leanness for aesthetic reasons, and improved performance $[25,26]$.

There was no significant difference between male and female respondents in this study in practising RWL. This finding contradicts the results of the study by Galli and Reel [27]. According to them, the objectives of rapid weight loss differed between male and female athletes. Most male athletes practised RWL to gain muscle and reduce fat in order to have a muscular and stronger body. Unlike male athletes, female athletes have been found to be more concerned with their weight and ideal
Table 4. Perceived adverse effects of RWL $(n=65)$

\begin{tabular}{|l|c|c|}
\hline & $\mathbf{n}(\%)$ & Mean (SD) \\
\hline Total score & & $3.7(2.81)$ \\
\hline Short-term memory loss & $7(10.8)$ & \\
\hline Decreased vigour & $33(50.8)$ & \\
\hline Decreased concentration & $28(43.1)$ & \\
\hline Increased depression & $16(24.6)$ & \\
\hline Fatigue & $45(69.2)$ & \\
\hline Muscle cramps & $30(46.2)$ & \\
\hline Increased rage & $19(29.2)$ & \\
\hline Increased risk of injury & $22(33.8)$ & \\
\hline Help in winning competition & $27(41.5)$ & \\
\hline
\end{tabular}

Table 5. Rapid weight loss based on socio-demographic and combat sport profiles $(n=65)$

\begin{tabular}{|c|c|c|c|}
\hline & \multicolumn{2}{|c|}{$\begin{array}{c}\text { RWL practice } \\
\mathrm{n}(\%) / \text { mean }(\mathrm{SD})\end{array}$} & \multirow[t]{2}{*}{$p$ value } \\
\hline & Yes & No & \\
\hline Age (year)a & $23.0(6.58)$ & $22.6(7.37)$ & 0.801 \\
\hline Genderb & & & 0.591 \\
\hline Male & $29(65.9)$ & $15(34.1)$ & \\
\hline Female & $14(66.7)$ & $7(33.3)$ & \\
\hline Ethnicityb & & & 0.140 \\
\hline Malay & $19(73.1)$ & $7(26.9)$ & \\
\hline Chinese & $11(50.0)$ & $11(50.0)$ & \\
\hline Others & $13(76.5)$ & $4(23.5)$ & \\
\hline Type of sport practised ${ }^{b}$ & & & $\mathrm{n} / \mathrm{a}^{*}$ \\
\hline Taekwondo & $14(48.3)$ & $15(51.7)$ & \\
\hline Muay thai & $13(92.9)$ & $1(7.1)$ & \\
\hline Other (judo, karate, silat) & $8(61.5)$ & $5(38.5)$ & \\
\hline Jiu jitsu & $8(88.9)$ & $1(11.1)$ & \\
\hline \multicolumn{4}{|l|}{ Perceived influence on weight loss ${ }^{b}$} \\
\hline Training colleague & $29(67.4)$ & $14(32.6)$ & $<0.01$ \\
\hline Physician/doctor & $8(18.6)$ & $35(81.4)$ & $<0.01$ \\
\hline Physical trainer & $33(76.7)$ & $10(23.3)$ & $<0.01$ \\
\hline Coach & $40(93.0)$ & $3(7.0)$ & $\mathrm{n} / \mathrm{a}^{*}$ \\
\hline Parents & $17(39.5)$ & $26(60.5)$ & $<0.01$ \\
\hline Dietician & $10(23.3)$ & $33(76.7)$ & $<0.01$ \\
\hline Former athlete & $24(55.8)$ & $19(44.2)$ & $<0.01$ \\
\hline Perceived adverse effects of RWLa & $4.2(2.06)$ & $2.6(3.70)$ & 0.034 \\
\hline
\end{tabular}

* - analysis was impossible to perform due to insufficient cell number,

a - independent samples t-test, ${ }^{\mathrm{b}}$ - Chi-square/Fisher's exact test.

body shape and constantly maintained their body weight within the desired range [28]. However, in terms of the RWL techniques used, female athletes were more susceptible to developing eating disorders, using harmful weight-control methods such as diuretics, laxatives, vomiting, and diet pills [27]. Male athletes, on the other hand, preferred to use dieting, sauna, and steam baths to regulate their body weight [9].

The average body weight reduction before the competition in the study was $4.9 \mathrm{~kg}(\mathrm{SD}=3.16)$, and $37.2 \%$ of those who 
practised RWL reported that they would take less than 7 days to reduce their weight before competition. This finding is consistent with the results of a study conducted among taekwondo athletes, where the body weight reduction was within the range of 4-6 kg; however, in terms of the duration of reducing weight, our study reported a shorter duration (7 days) compared to the 10-20 days in the taekwondo study [29]. The most frequently used methods in our study were exercising more $(69.8 \%)$, gradual dieting (51.1\%), and training in heated rooms (20.8\%), which is consistent with the findings of studies where techniques like increased exercise, restriction of food intake, training in heated rooms, gradual dieting, and fluid restriction were commonly used $[13,14]$. The more extreme methods such as diuretics, vomiting, diet pills, and spitting were reported less often; more than $60 \%$ of the respondents in the study claimed they had never used these methods. Perhaps these extreme methods are found to a greater extent among elite combat athletes who participate in more competitive events at the national and international levels. Nevertheless, Oppliger et al. [13] and Kiningham and Gorenflo [14] have concluded that harmful weight loss practices are common at all levels of combat sports competitions regardless of the competitive level or the number of matches won or lost. On the other hand, Artioli et al. [5] discovered in their study that combat athletes who were switching to a different weight category, particularly those moving from a heavier to lower weight category, presented a more aggressive approach in weight management compared to those who remained in their existing weight category.

The findings of this study indicate that the persons who influenced athletes the most in the decision to reduce their weight were physical trainers and training colleagues, consistently with the literature $[3,4,6]$. Physicians and dieticians were perceived as persons who had less influence on the weight management of the respondents, a result that was anticipated as such support is not available at the club or association level. It is only elite athletes competing at the national or international levels who benefit from a structured support system in the form of proper medical and scientific support. Because physicians and dieticians are professionals, their input and guidance can help combat athletes in managing their weight in a healthy way. Parents also play an important role in influencing their children who are participating in combat sports. More educational programmes should be put in place to assist parents in helping their children to manage their weight properly.

Rapid weight loss is associated with negative health and performance outcomes if it is not done appropriately. Potential immediate and long-term consequences of rapid weight loss whether physiological, cognitive, psychological, performancerelated, or health-related - have been observed among different combat athletes $[9,30]$. Except for short-term memory loss, which had the lowest score, the respondents in this study were aware of most of the adverse effects of rapid weight loss, its impact ranging from effects on mental to physical well-being. When a comparison was done between those who practised RWL and those who did not, it was found that the mean score for knowledge of the adverse effects of RWL was higher among those who practised RWL. In their qualitative study, Petterson, Ekström, and Berg [18] explained that most combat athletes viewed rapid weight loss as helpful in gaining physical and mental dominance in competitions. Pursuing weight loss was perceived as a part of combat athletes' preparation to compete, and by adhering to a weight-loss plan, the athletes themselves had gained confidence - a key to winning. Therefore, it is important to provide additional education on appropriate weight loss methods that are less harmful - but successful - in order to minimise the risk of over-reaching and over-training [26].

A limitation of the current study is the sample size, which may affect the generalisation of the findings. Although it was not based on convenience sampling, equal representation of each combat sport was not achieved due to limited sample size. Moreover, the results were based on retrospective self-reported data; therefore, response bias was unavoidable.

\section{Conclusion}

In conclusion, this study provides preliminary findings on the prevalence and profile of rapid weight loss among combat athletes in Kuching. Although this study focused on non-elite combat athletes, the findings were found to be similar to those regarding elite combat sport athletes. Since RWL is a common practice among athletes of different levels and, if not done properly, can have negative effects on the athletes, an adequate regulatory programme should be put in place to assist both the athletes and their coaches/trainers in proper weight control. There should also be an individual approach to the selection of weight loss methods allowed to prevent any unwanted negative effects on the athletes. The dissemination of knowledge concerning the negative effects of RWL should focus on all age groups and both genders. Educational programmes that include both training and nutrition components should be introduced at community and organisational levels to help the athlete's community and their family in gearing towards healthy living.

\section{Acknowledgements}

We would like to acknowledge the support and assistance given by the clubs and associations that participated in our study.

\section{Literature}

1. Cynarski W.J., Kudlacz M. (2008). Injuries in martial arts and combat sports - A comparative study. Archives of Budo 4, 91-97.

2. Pappas E. (2007). Boxing, wrestling, and martial arts related injuries treated in emergency departments in the United States, 2002-2005. Journal of Sports Science and Medicine 6, 58-61.

3. Noh J.W., Kim J.H., Kim J.H. (2013). Somatotype analysis of Korean wrestling athletes compared with non-athletes for sports health sciences. Toxicology and Environmental Health Sciences 5(3), 163-168.

4. Iide K., Imamura H., Yoshimura Y., Yamashita A., Miyahara K., Miyamoto N. et al. (2008). Physiological responses of simulated karate sparring matches in young men and boys. Journal of Strength and Conditioning Research 22(3), 839844. DOI: 10.1519/JSC.0b013e31816a5af6.

5. Artioli G.G., Gualano B., Franchini E., Scagliusi F.B., Takesian M., Fuchs M. et al. (2010). Prevalence, magnitude, and methods of rapid weight loss among judo competitors. $\mathrm{Me}$ dicine and Science in Sports and Exercise 42(3), 436-442. DOI: 10.1249/MSS.0b013e3181ba8055.

6. Franchini E., Takito M.Y., Kiss M.A.P.D.M., Sterkowicz S. (2005). Physical fitness and anthropometrical differences between elite and non-elite judo players. Biology of Sport 22(4), 315-328.

7. Dubnov-Raz G., Mashiach-Arazi Y., Nouriel A., Raz R., Constatini N.W. (2015). Can height categories replace weight 
categories in striking martial arts competitions? A pilot study. Journal of Human Kinetics 47, 91-98. DOI: 10.1515/hukin-2015-0065.

8. Khodaee M., Olewinski L., Shadgan B., Kiningham R.R. (2015). Rapid weight loss in sports with weight classes. Current Sports Medicine Report 14(6), 435-441. DOI: 10.1249/ JSR.0000000000000206.

9. Artioli G.G., Franchini E., Nicastro H., Sterkowicz S., Solis M.Y., Lancha Jr. A.H. (2010). The need of a weight management control program in judo: A proposal based on the successful case of wrestling. Journal of the International Society of Sports Nutrition 7(15). DOI: 10.1186/1550-2783-7-15.

10. Malliaropoulos N., Rachid S., Korakakis V., Fraser S.A., Bikos G., Maffulli N. et al. (2017). Prevalence, techniques and knowledge of rapid weight loss amongst adult British judo athletes: A questionnaire based study. Muscles, Ligaments and Tendons Journal 7(3), 459-466. DOI: 10.11138/ mltj/2017.7.3.459.

11. Brito C.J., Roas A.F.C.M., Brito I.S.S., Marins J.C.B., Cordova C., Franchini E. (2012). Methods of body-mass reduction by combat sport athletes. International Journal of Sport Nutrition and Exercise Metabolism 22(2), 89-97.

12. Langan-Evans C., Close G., Morton J. (2011). Making weight in combat sports. Strength and Conditioning Journal 33(6), 25-39. DOI: 10.1519/SSC.0b013e318231bb64.

13. Oppliger R.A., Steen S.N., Scott J.R. (2003). Weight loss practice in college wrestling. International Journal of Sport Nutrition and Exercise Metabolism 13(1), 29-46.

14. Kiningham R.B., Gorenflo D.W. (2001). Weight loss methods of high school wrestlers. Medicine and Science in Sports and Exercise 33(5), 810-813.

15. Ng Q.X., Choe Y.X., Karppaya H., Chai W.J., Ramadas A. (2017). Rapid weight loss practices among elite combat sports athletes in Malaysia. Malaysian Journal of Nutrition 23(2), 199-209.

16. Degoutte F., Jouanel P., Begu, R.J., Colombier M., Lac G., Pequignot J.M. et al. (2006). Food restriction, performance, biochemical, psychological, and endocrine changes in judo athletes. International Journal of Sports Medicine 27(1), 9-18. DOI: 10.1055/s-2005-837505.

17. Hall C.J., Lane A.M. (2001). Effects of rapid weight loss on mood and performance among amateur boxers. British Journal of Sports Medicine 35(6), 390-395.

18. Pettersson S., Ekström M.P., Berg C.M. (2013). Practices of weight regulation among elite athletes in combat sports: A matter of mental advantage? Journal of Athletic Training 48(1), 99-108. DOI: 10.4085/1062-6050-48.1.04.
19. Kons R.L., Da Silva Athayde M.S., Follmer B., Detanico D. (2017). Methods and magnitudes of rapid weight loss in judo athletes over pre-competition periods. Human Movement 18(2), 49-55. DOI: 10.1515/humo-2017-0014.

20. Dhand N.K., Khatkar M.S. (2014). Statulator: An online statistical calculator. Sample size calculator for estimating a single proportion. Accessed 16 October 2017 at http://statulator.com/SampleSize/sslP.html.

21. Artioli G.G., Scagliusi F., Kashiwagura D., Franchini E., Gualano B., Junior A.L. (2010). Development, validity and reliability of a questionnaire designed to evaluate rapid weight loss patterns in judo players. Scandinavian Journal of Medicine and Science Sports 20(1), 177-187. DOI: 10.1111/j. 1600-0838.2009.00940x.

22. Steen S.N., Brownell K.D. (1990). Patterns of weight loss and regain in wrestlers: Has the tradition changed? Medicine and Science in Sports and Exercise 22(6), 762-768.

23. Artioli G.G., Gualano B., Franchini E., Batista R.N., Polacow V.O., Lancha A.H. (2009). Physiological, performance, and nutritional profile of the Brazilian Olympic Wushu (KungFu) team. Journal of Strength and Conditioning Research 23(1), 20-25. DOI: 10.1519/JSC.0b013e318187687a.

24. Smith M. (1996). Fluid balance in weight categorized sports. Coaching 8, 22.

25. Reel J., SooHoo S., Petrie T.A., Greenleaf C., Carter J.E. (2010). Slimming down for sport: Developing a weight pressures in sport measure for female athletes. Journal of Clinical Sport Psychology 4(2), 99-111. DOI: 10.1123/jcsp.4.2.99.

26. Wilson P.B., Madrigal L., Burnfield J.M. (2016). Weight control practices of Division I National Collegiate Athletic Association athletes. The Physician and Sportmedicine 44(2), 170-176. DOI: 10.1080/00913847.2016.1149420.

27. Galli N., Reel J.J. (2009). Adonis or Hephaestus? Exploring body image in male athletes. Psychology of Men E Masculinity 10(2), 95-108. DOI: 10.1037/a0014005.

28. Tackett B.P., Petrie T.A., Anderson C.M. (2016). The frequency of weigh-ins, weight intentionality and management, and eating among female collegiate athletes. Eating Behaviors 23, 82-85. DOI: 10.1016/j.eatbeh.2016.08.007.

29. Santos J.F.D.S., Takito M.Y., Artioli G.G., Franchini E. (2016). Weight loss practices in Taekwondo athletes of different competitive levels. Journal of Exercise Rehabilitation 12(3), 202-208. DOI: 10.12965/jer.1632610.305.

30. Turocy P.S., DePalma B.F., Horswill C.A., Laquale K.M., Martin T.J., Perry A.C. et al. (2011). National Athletic Trainers' Association position statement: Safe weight loss and maintenance practices in sport and exercise. Journal of Athletic Training 46(3), 322-336.

Submitted: December 5, 2018.

Accepted: February 8, 2019. 